\title{
Anesthetic Consideration of a Patient with McCune-Albright Syndrome: A Case Report
}

\author{
Se Hee Kang, Ji Seon Jeong \\ Department of Anesthesiology and Pain Medicine, Samsung Seoul Hospital, Seoul, Republic of Korea \\ Email: jiseon78.jeong@samsung.com
}

How to cite this paper: Kang, S.H. and Jeong, J.S. (2016) Anesthetic Consideration of a Patient with McCune-Albright Syndrome: A Case Report. Open Journal of Anesthesiology, 6, 187-192.

http://dx.doi.org/10.4236/ojanes.2016.611028

Received: October 14, 2016

Accepted: November 27, 2016

Published: November 30, 2016

Copyright $\odot 2016$ by authors and Scientific Research Publishing Inc. This work is licensed under the Creative Commons Attribution International License (CC BY 4.0).

http://creativecommons.org/licenses/by/4.0/

\begin{abstract}
The McCune-Albright syndrome is rare disease diagnosed by the clinical triad, fibrous dysplasia, café-au lait skin pigmentations and endocrine hyperfunction. Those patients with bone issues could have various surgeries under general anesthesia. Airway abnormality and various endocrine abnormalities should be considered during general anesthesia for McCune-Albright syndrome patients. A 15-year-old male with McCune-Albright syndrome was admitted with complaint of right nasal obstruction originated from fibrous dysplasia. Endoscopic resection of nasal cavity lesion was scheduled under navigation system guidance. Difficult airway could be anticipated due to protrusion of maxilla and right nostril. Awake fiberoptic intubation was performed by spray-as-you-go technique. When an anesthesiologist expects to take care of the patient with the McCune-Albright syndrome, the most appropriate anesthetic induction and tracheal intubation technique should be selected, and multiple backup instruments such as supraglottic device, video laryngoscope and fiberoptic bronchoscopy should be prepared.
\end{abstract}

\section{Keywords}

Difficult Intubation, Fibrous Dysplasia, McCune-Albright Syndrome

\section{Introduction}

The McCune-Albright syndrome is uncommon disease, first described in 1937. Fibrous dysplasia, café-au lait skin pigmentations and endocrine hyperfunction are the clinical triad for diagnosis.

Estimated prevalence was between 1/100,000 and 1/1000,000 [1] [2]. Central precocious puberty, congenital adrenal hyperplasia, neurofibromatosis, ossifying fibrous dysplasia, thyrotoxicosis and various congenital syndrome associated with hydrocephalus should be considered as differential diagnosis [2] [3] [4]. 
The McCune-Albright syndrome is the result og an activating mutation go the cAMP regulating protein, GNAS1 Gene product, and Gs. Most Gs mutations are point mutation at the Arg201 position, with the majority being arg201 His or Cys.

At the McCune-Albright syndrome, femur and craniofacial bone could be commonly involved for fibrous dysplasia [4]. Fibrous dysplasia of the craniofacial bones can lead visual disorder, exophthalmos, nasal obstructions, asymmetry of face and hearing impairment. In addition to that, the progression of fibrous dysplasia affecting craniofacial bone is associated with difficult airway. Recently, we performed anesthesia on a patient with the McCune-Albright syndrome who had fibrous dysplasia on craniofacial bone.

\section{Case Report}

A 15-year-old, $184 \mathrm{~cm}, 89.2 \mathrm{~kg}$ boy was admitted with complaint of right nasal obstruction due to fibrous dysplasia. Navigation system guided endoscopic nasal surgery was decided. The McCune-Albright syndrome was diagnosed at eight years ago by multiple café-au lait spot, fibrous dysplasia and growth hormone abnormality. The patient had the open reduction and internal fixation operation for pathologic femur fracture and the endoscopic resection of nasal cavity for fibrous dysplasia at eight and three years ago. At previous surgery, airway examination was within normal range. The patient took pamidronate (a bisphosphonate) to control fibrous dysplasia.

Laboratory test, urinalysis and chest $\mathrm{x}$-ray was within normal range. Pituitary function tests indicated slightly increased IGF-1. Thyroid and parathyroid function tests were normal (Table 1). Partial suppression was observed on GH suppression test. Suspected pituitary adenoma was observed in sellar magnetic resonance imaging. Progression of fibrous dysplasia in both nasal cavities was observed in the facial CT (Figure $1(\mathrm{~A}))$.

In physical examination, mouth opening, neck extension, and thyromental distance were within normal range but, Mallampati grade 4 was observed due to oral cavity protrusion of maxilla and right nostril (Figure 1(B)). Difficult mask ventilation and intubation were expected.

Table 1. Endocrine lab count.

\begin{tabular}{ccc}
\hline & The patient's & Normal lab count \\
\hline IGF-1 $(\mathrm{ng} / \mathrm{ml})$ & 675.2 & $232-385$ \\
FSH $(\mathrm{mIU} / \mathrm{ml})$ & 4.0 & $1.4-18.1$ \\
LH $(\mathrm{mIU} / \mathrm{ml})$ & 3.0 & $1.5-9.3$ \\
TSH $(\mathrm{mIU} / \mathrm{ml})$ & 1.749 & $0.55-4.78$ \\
Free $\mathrm{T} 4(\mathrm{ng} / \mathrm{dl})$ & 0.97 & $0.89-1.8$ \\
T3 $(\mathrm{ng} / \mathrm{dl})$ & 108.18 & $76-190$ \\
Ca $(\mathrm{mg} / \mathrm{dl})$ & 9.5 & $8.4-10.2$ \\
P $(\mathrm{mg} / \mathrm{dl})$ & 3.0 & $2.5-4.5$ \\
\hline
\end{tabular}



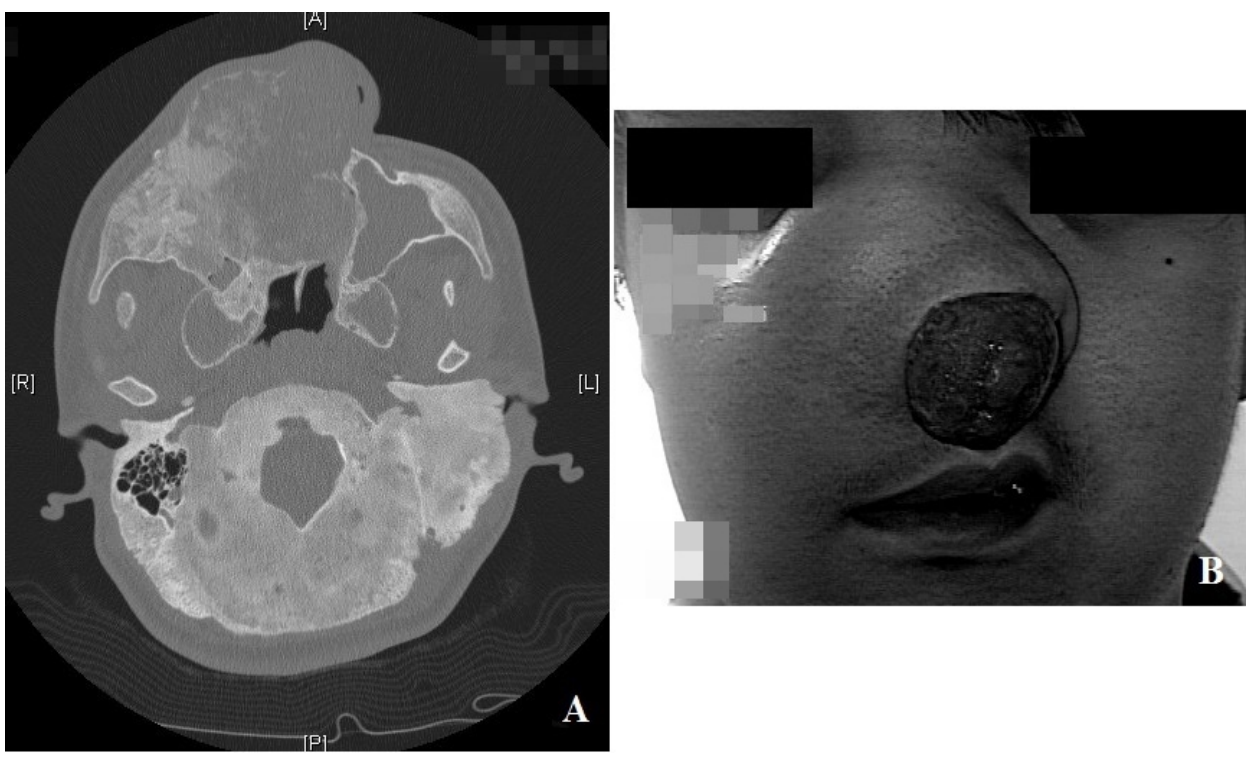

Figure 1. (A) The facial CT was showed fibrous dysplasia of facial bone; (B) right nostril's severe protrusion.

The awake fiberoptic intubation was prepared. As premedication, the patient received glycopyrrolate $0.2 \mathrm{mg}$ intravenous injection 30 minutes before the operation. When the patient was entered into the operating room, general monitoring including ECG, noninvasive blood pressure, pulse oxymetry and bispectral index monitoring (BIS) was initiated. After $1 \%$ lidocaine local infiltration on the forearm, angiocatheter was inserted into radial artery for invasive blood pressure monitor before anesthesia induction.

Oxygen was administrated at $4 \mathrm{~L} / \mathrm{min}$ through oxygen mask during awake fiberoptic intubation. Remifentanil was administrated by a target-controlled infusion system (Orchestra ${ }^{\oplus}$, Fresenius Vial, France). The target concentration of remifentanil was set at $3.0 \mathrm{ng} / \mathrm{ml}$ and target concentration was titrated up or down to achieve adequate sedation. Before fiberoptic intubation, 10\% xylocaine spray was applied to pharynx. After 5 minutes, awake fiberoptic intubation was tried. Spray-as-you-go technique that $2 \% \mathrm{li}$ docaine was applied through the suction channel was used [5]. Awake fiberoptic intubation with \#8.0 endotracheal tube was successfully done at the first attempt without coughing and other complication. After intubation, the target concentration of propofol was raised to $4.0 \mathrm{ng} / \mathrm{kg}$ and rocuronium $0.6 \mathrm{mg} / \mathrm{kg}$ was injected.

Anesthesia was maintained with TIVA guided by a BIS (40 and 60). The surgery was over uneventfully. After surgery, the intubated patient with spontaneous breathing was moved to the Intensive Care Unit (ICU). In the ICU, no other sedation drug injected to the patient. Only hydromorphone injected to him for controlling the surgical wound pain. On the first day after surgery, endotracheal tube was extubated and the patient was moved to the general ward. The patient discharged from the hospital at POD 5 without complications. 


\section{Discussion}

The McCune-Albright syndrome is a genetic disease characterized by fibrous dysplasia involving bone structure with endocrine hyperfunction and café-au lait skin spot [1].

At the McCune-Albright syndrome, polyostotic fibrous bone dysplasia are observed in approximately $20 \%-30 \%$ patients (femur $(91 \%)$, tibia $(81 \%)$, pelvis $(78 \%)$ and craniofacial bone (50\%)) [6]. In MAS, normal bone could be replaced by benign fibroosseous tissue and it often leads bone fracture [7]. Therefore, patient positioning should be done carefully. Our patient took surgery for femur fracture and fibrous dysplasia affecting nasal cavity at eight and three years ago, respectively. After surgical treatment, the patient had started to take Pamidronate (Bisphosphate) to control fibrous dysplasia. It can be useful to control bone pain and reduce pathologic fracture rate [2]. But it was not helpful to our patient. As the fibrous dysplasia affecting craniofacial bone is exacerbated, the airway was changed. When he took endoscopic resection of nasal cavity three years ago, his airway was normal but slight nasal obstruction was reported. However, the patient suffered from both nasal obstruction and right nostril's severe protrusion due to the progression of maxillary fibrous dysplasia at the time of this surgery. Mask ventilation and $\mathrm{O}_{2}$ application through nasal cannula was expected to be limited.

Mallampati classification, upper lip bite test, and thyromental distance can be used to predict difficult airway. In patients with the McCune-Albright syndrome, the usefulness of those predictors for difficult airway is skeptical [8]. In our patient, mouth opening, neck extension, and thyromental distance was normal but Mallampati grade 4 was observed in airway examination.

Growth hormone hypersecretion is common in the McCune-Albright syndrome and acromegaly can appear [4]. With acromegaly, small low jaw and large tongue can impede larynx visualization. The laboratory result of our patient revealed the Growth hormone hypersecretion. He had enlarged hands, feet, tongue, larynx and pharyngeal soft tissue hypertrophy. But he didn't have mandibular overgrowth, prognathism, brow ridge and forehead protrusion. Enlarged larynx can require a larger endotracheal tube [9]. Larger endotracheal tube was used than a child of his age. Endotracheal cuff was not too tight, so air was leaked at $20 \mathrm{~cm} \mathrm{H}_{2} \mathrm{O}$. Based on physical examination, awake fiberoptic intubation was planned. In awake fiberoptic intubation, $\mathrm{O}_{2}$ was usually supplied through nasal cannula. But in this case, because of both nasal obstructions, $\mathrm{O}_{2}$ was delivered to mouth using oxygen supply tube. During awake fiberoptic intubation, the patient's saturation was stayed at $100 \%$. Nose, mouth, tongue and pharynx were anesthetized with topical anesthesia, and glossopharyngeal, superior laryngeal nerve block, recurrent nerve block (transtracheal block) could be perfomed but it is not mandatory procedure for awake fiberoptic intubation [10] [11]. Because of airway abnormality by fibrous dysplasia of facial bone, Nerve block was not tried, because it seems likely that MAS modified airway anatomy. After $10 \%$ xylocaine spray was applied to pharynx, spray-as-you-go technique that $2 \%$ lidocaine was applied through the suction channel was done. Remifentanil was administrated for sedation and analgesia. The awake fiberoptic intubation was successful without other complication. 


\section{Conclusion}

The anesthetic consideration of the patients with McCune-Albright syndrome has two main problems, endocrine abnormalities and difficult airway management. Therefore, the patients with McCune-Albright syndrome expecting scheduled surgery require perioperative management by endocrinologist, because hyperthyroidism, Cushing's disease, acromegaly, hyperprolactinemia, hyperparathyroidism and sexual precocity are common in those patients [1] [2]. And the anesthesiologist should select the most appropriate method of anesthetic induction and tracheal intubation, and prepare several intubation devices such as supraglottic device, video laryngoscope and fiberoptic bronchoscopy, etc.

\section{References}

[1] Langer, R.A., Yook, I. and Capan, L.M. (1995) Anesthetic Considerations in McCuneAlbright Syndrome: Case Report with Literature Review. Anesthesia \& Analgesia, 80, 12361239.

[2] Dumitrescu, C.E. and Collins, M.T. (2008) McCune-Albright Syndrome. Orphanet Journal of Rare Diseases, 3, 12. https://doi.org/10.1186/1750-1172-3-12

[3] Sharma, A. and Kulkarni, D.K. (2009) Anticipation, Planning and Execution of Airway Strategy in McCune-Albright's Syndrome. Pediatric Anesthesia, 19, 637-638. https://doi.org/10.1111/j.1460-9592.2008.02919.x

[4] Sung, S.H., Yoon, H.D., Shon, H.S., Kim, H.T. and Choi, W.Y. (2007) A Case of McCuneAlbright Syndrome with Associated Multiple Endocrinopathies. The Korean Journal of Internal Medicine, 22, 45-50. https://doi.org/10.3904/kjim.2007.22.1.45

[5] Xue, F.S., Liu, H.P., He, N., Xu, Y.C., Yang, Q.Y., Liao, X., et al. (2009) Spray-as-You-Go Airway Topical Anesthesia in Patients with a Difficult Airway: A Randomized, DoubleBlind Comparison of $2 \%$ and 4\% Lidocaine. Anesthesia \& Analgesia, 108, 536-543. https://doi.org/10.1213/ane.0b013e31818f1665

[6] Prada, E.J., Hassan, K.H., Brandi, M.L. and Falchetti, A. (2009) Polyostotic Form of Fibrous Dysplasia in a 13 Years Old Colombian Girl Showing Clinical and Biochemical Response to Neridronate Intravenous Therapy. Clinical Cases in Mineral and Bone Metabolism, 6, 264-265.

[7] Leet, A.I., Chebli, C., Kushner, H., Chen, C.C., Kelly, M.H., Brillante, B.A., et al. (2003) Fracture Incidence in Polyostotic Fibrous Dysplasia and the McCune-Albright Syndrome. Journal of Bone and Mineral Research, 19, 571-577. https://doi.org/10.1359/JBMR.0301262

[8] Chakravarty, C., Yadav, N., Ali, Z. and Prabhakar, H. (2010) Upper Lip Bite Test in a Patient with McCune Albright Syndrome with Acromegaly. Journal of Clinical Neuroscience, 17, 258-259. https://doi.org/10.1016/j.jocn.2009.05.021

[9] Koc, D., Bayri, Y. and Seker, A. (2014) Anesthetic Management of an Acromegalic Patient with McCune Albright Syndrome for Endoscopic Transsphenoidal Adenoma Removal. Journal of Neurosurgical Anesthesiology, 26, 267-269. https://doi.org/10.1097/ANA.0000000000000008

[10] Mingo, O.H., Ashpole, K.J., Irving, C.J. and Rucklidge, M.W.M. (2008) Remifentanil Sedation for Awake Fibreoptic Intubation with Limited Application of Local Anaesthetic in Patients for Elective Head and Neck Surgery. Anaesthesia, 63, 1065-1069.

https://doi.org/10.1111/j.1365-2044.2008.05567.x 
[11] Hu, R., Liu, J.X. and Jiang, H. (2012) Dexmedetomidine versus Remifentanil Sedation during Awake Fiberoptic Nasotracheal Intubation: A Double-Blinded Randomized Controlled trial. Journal of Anesthesia, 27, 211-217. https://doi.org/10.1007/s00540-012-1499-y

Submit or recommend next manuscript to SCIRP and we will provide best service for you:

Accepting pre-submission inquiries through Email, Facebook, LinkedIn, Twitter, etc. A wide selection of journals (inclusive of 9 subjects, more than 200 journals)

Providing 24-hour high-quality service

User-friendly online submission system

Fair and swift peer-review system

Efficient typesetting and proofreading procedure

Display of the result of downloads and visits, as well as the number of cited articles Maximum dissemination of your research work

Submit your manuscript at: http://papersubmission.scirp.org/

Or contact ojanes@scirp.org 